\title{
Clinical utility of lenalidomide in the treatment of myelodysplastic syndromes
}

\author{
This article was published in the following Dove Press journal: \\ Journal of Blood Medicine \\ 22 December 2014 \\ Number of times this article has been viewed
}

\section{Abdallah Abou Zahr' \\ Ehab Saad Aldin ${ }^{2}$ \\ Rami S Komrokji ${ }^{3}$ \\ Amer M Zeidan ${ }^{4}$}

'Section of Hematology/Oncology, Department of Internal Medicine, Mount Sinai Beth Israel, New York City, New York, NY, ${ }^{2}$ Department of Internal Medicine, Medstar Good Samaritan Hospital, Baltimore, MD, ${ }^{3}$ Department of Malignant Hematology, H Lee Moffitt Cancer Center and Research Institute, Tampa, FL, ${ }^{4}$ Division of Hematology, Department of Medicine, Yale University, New Haven, CT, USA
Correspondence: Amer M Zeidan Section of Hematology, Department of Internal Medicine, Yale University, 333 Cedar Street, PO Box 208028, New Haven, CT 06520, USA

$\mathrm{Tel}+\mathrm{I} 2037377103$

Fax +I 2037857232

Email amer.zeidan@yale.edu
Abstract: Myelodysplastic syndromes (MDS) represent a heterogeneous group of acquired clonal hematopoietic disorders characterized by peripheral blood cytopenias, paradoxical BM hypercellularity, ineffective hematopoiesis, and increased risk of leukemic transformation. Risk stratification, using different prognostic scores and markers, is at the core of MDS management. Deletion $5 q[\operatorname{del}(5 q)]$ MDS is a distinct class of MDS characterized by the haploinsufficiency of specific genes, microRNAs, and proteins, which has been linked to increased sensitivity to the drug lenalidomide. Phase II and III clinical trials have demonstrated the efficacy of lenalidomide in improving clinical outcomes of patients with $\operatorname{del}(5 q)$ MDS, including reduction in red blood cell transfusion requirements and improvements in quality of life. Lenalidomide has also demonstrated some activity in non-del(5q) lower-risk MDS as well as higher-risk MDS, especially in combination with other agents. In this paper, we review the pathogenesis of $\operatorname{del}(5 q)$ MDS, the proposed mechanisms of action of lenalidomide, the major clinical trials that documented the activity of lenalidomide in different MDS populations, potential predictors of benefit from the drug and suggested mechanisms of resistance, and the use of combination strategies to expand the clinical utility of lenalidomide in MDS.

Keywords: deletion 5q, lenalidomide, myelodysplastic syndromes, 5q-syndrome

\section{Introduction}

Myelodysplastic syndromes (MDS) include a heterogeneous group of acquired clonal hematopoietic malignancies characterized by an apparent paradox of peripheral blood cytopenias and bone marrow (BM) hypercellularity, ineffective hematopoiesis, and a variably increased risk of leukemic transformation. ${ }^{1,2}$ While MDS is usually characterized by BM hypercellularity, a minority of patients exhibit BM hypoplasia which can be difficult to distinguish from aplastic anemia. ${ }^{3}$ MDS incidence increases with age in the general population, and the number of diagnosed cases is expected to increase with the increasing longevity of the population. ${ }^{4-11}$ Risk stratification is at the core of current MDS management, ${ }^{10-12}$ and is accomplished using different prognostication schemes that group patients into different risk categories based on factors such as number and severity of cytopenias, karyotypic abnormalities, BM blast percentage, and transfusion dependence. ${ }^{13}$ The most widely used prognostic scores are the International Prognostic Scoring System (IPSS) and its revised version (IPSS-R), the World Health Organization Classification-Based Prognostic Scoring System, the MD Anderson prognostic schemes, and others. ${ }^{14-20}$

Only a limited number of therapeutic options currently exist for MDS, and their use is usually guided by clinical risk stratification tools rather than specific biological 
markers, with the notable exception of the 5q-cytogenetic deletion that predicts particular sensitivity to lenalidomide in lower-risk MDS patients. ${ }^{11-13}$ Lenalidomide, a thalidomide analog, is an immunomodulatory agent that has demonstrated clinical efficacy in MDS patients with low to intermediate IPSS scores and a deletion in the long arm of chromosome $5[\operatorname{del}(5 \mathrm{q})] .^{21,22}$ Lenalidomide has also demonstrated some activity, although less impressive, in MDS patients outside this group. Several studies have tried to identify factors beyond $\operatorname{del}(5 \mathrm{q})$ that might predict response to lenalidomide. ${ }^{13}$ Lenalidomide is also being evaluated in combination with other agents used to treat MDS, including hypomethylating agents in higher-risk MDS patients and erythropoiesis-stimulating agents (ESAs) in lower-risk MDS patients. $^{23,24}$ This paper reviews the pathogenesis of $\operatorname{del}(5 \mathrm{q})$ MDS, the proposed mechanisms of action of lenalidomide, the major clinical trials that documented the activity of lenalidomide in different MDS populations, potential predictors of benefit from the drug and suggested mechanisms of resistance, and the use of combination strategies to expand the clinical utility of lenalidomide in MDS.

\section{Pathogenesis of del(5q) MDS}

The pathogenesis of $\operatorname{del}(5 q)$ MDS is likely related to deletion of various genes that are important for normal erythropoiesis and cell cycle regulation. ${ }^{25-28}$ The long arm of chromosome 5 (5q), particularly the $5 \mathrm{q} 31$ region, has a gene cluster that is relevant to hematopoiesis. ${ }^{25}$ This gene cluster includes interleukin (IL)-3, IL-4, IL-5, IL-9, IL-13, and IL-17ß, as well as granulocyte-monocyte colony stimulating factor and several cytokine receptor genes (colony-stimulating factor 1 receptor and platelet-derived growth factor- $\beta$ ). ${ }^{26-28}$ The hallmark of 5q-syndrome is an isolated interstitial deletion on the long arm of chromosome 5. The 5q-syndrome was first characterized in 1974 by Van Den Berghe et al. ${ }^{29}$
Clinically, the 5q-syndrome is typically characterized by macrocytic hypoproliferative anemia, hypolobulated micromegakaryocytes, fewer than 5\% BM blasts, normal or increased platelet counts, and a tendency to occur in older women. ${ }^{22,30}$ MDS with isolated $\operatorname{del}(5 \mathrm{q})$ or with additional chromosomal abnormalities is not entirely clinically equivalent to 5q-syndrome. However, because the 5q-syndrome and MDS associated with del $(5 q)$ are both sensitive to lenalidomide, the World Health Organization classification puts them under one special category, ie, MDS with chromosome 5 q deletion. ${ }^{31}$ The 5q-syndrome occurs only in a subgroup of patients with $\operatorname{del}(5 \mathrm{q})$. The commonly deleted region in 5q-syndrome is 5q32-33. This region is known as the distal common deleted region $(\mathrm{CDR})$. Another region frequently deleted in patients with del(5q) MDS or acute myeloid leukemia (AML) is a 1 to 1.5 megabase region at chromosome $5 \mathrm{q} 31$. This region is known as the proximal CDR. Genes in the CDR, their effect, and the potential effects of lenalidomide on the haplodeficient genes are listed in Table $1 .^{32}$

\section{Haploinsufficiency of RPS I4}

RPS14 is a ribosomal protein essential for the assembly of the ribosomal complex. ${ }^{33}$ Ebert et al demonstrated that the haploinsufficiency of RPS14 results in erythroid differentiation defects and that its forced expression in cells from patients with 5 q-syndrome promotes erythroid differentiation. ${ }^{33}$ The potential mechanism of how ribosomal haploinsufficiency leads to impaired erythropoiesis is summarized in Figure 1. It is thought that RPS14 haploinsufficiency interferes with normal ribosomal biosynthesis, leading to accumulation of free ribosomal proteins. ${ }^{34}$ The free ribosomal proteins bind to murine double minute 2 (MDM2), blocking the binding of MDM2 to p53. This ultimately leads to accumulation of p53in erythroid progenitor cells, increasing apoptosis and impairing erythropoiesis. ${ }^{34,35}$

Table I Genes in the commonly deleted region, their effect, and potential effects of lenalidomide on the haplodeficient genes

\begin{tabular}{|c|c|c|c|c|}
\hline Gene & Effect of deletion & Phenotype & Effect of lenalidomide & $\begin{array}{l}\text { Functional effect of } \\
\text { lenalidomide }\end{array}$ \\
\hline RPS $/ 4^{33,93}$ & Defective ribosomal processing & Macrocytic anemia & Increased expression & Erythroid response \\
\hline $\begin{array}{l}\operatorname{miRNA}-145^{36} \\
\operatorname{miRNA} / 46 a^{21,36}\end{array}$ & $\begin{array}{l}\text { Elevated innate immune } \\
\text { signaling }\end{array}$ & $\begin{array}{l}\text { Thrombocytosis, neutropenia, } \\
\text { megakaryocytic dysplasia }\end{array}$ & Increased expression & Possible anti-inflammatory \\
\hline$C D C 25 c / P P 2 A^{94}$ & $\begin{array}{l}\text { Defective G2-M phase } \\
\text { regulation }\end{array}$ & $\begin{array}{l}\text { GI and G2 M arrest and } \\
\text { apoptosis }\end{array}$ & $\begin{array}{l}\text { Direct inhibition of CDC25c, } \\
\text { indirect inhibition of PP } 2 A\end{array}$ & $\begin{array}{l}\text { G2 arrest and apoptosis } \\
\text { Restoration of erythropoiesis }\end{array}$ \\
\hline$S P A R C^{38}$ & Increased cell adhesion & $\begin{array}{l}\text { Thrombocytopenia and } \\
\text { anemia }\end{array}$ & Increased expression & $\begin{array}{l}\text { Inhibition of proliferation and } \\
\text { adhesion }\end{array}$ \\
\hline$E G R I^{32}$ & Decrease in tumor suppressors & $\begin{array}{l}\text { Leukocytosis, anemia, } \\
\text { thrombocytopenia }\end{array}$ & Increased expression & Reduced proliferation \\
\hline DIAPH ${ }^{95}$ & $\begin{array}{l}\text { Defective cytoskeleton, tumor } \\
\text { suppression }\end{array}$ & Clonal dominance & Unknown & Unknown \\
\hline
\end{tabular}

Note: Gene list obtained from multiple sources. ${ }^{21,32,33,36,38,93-95}$ 


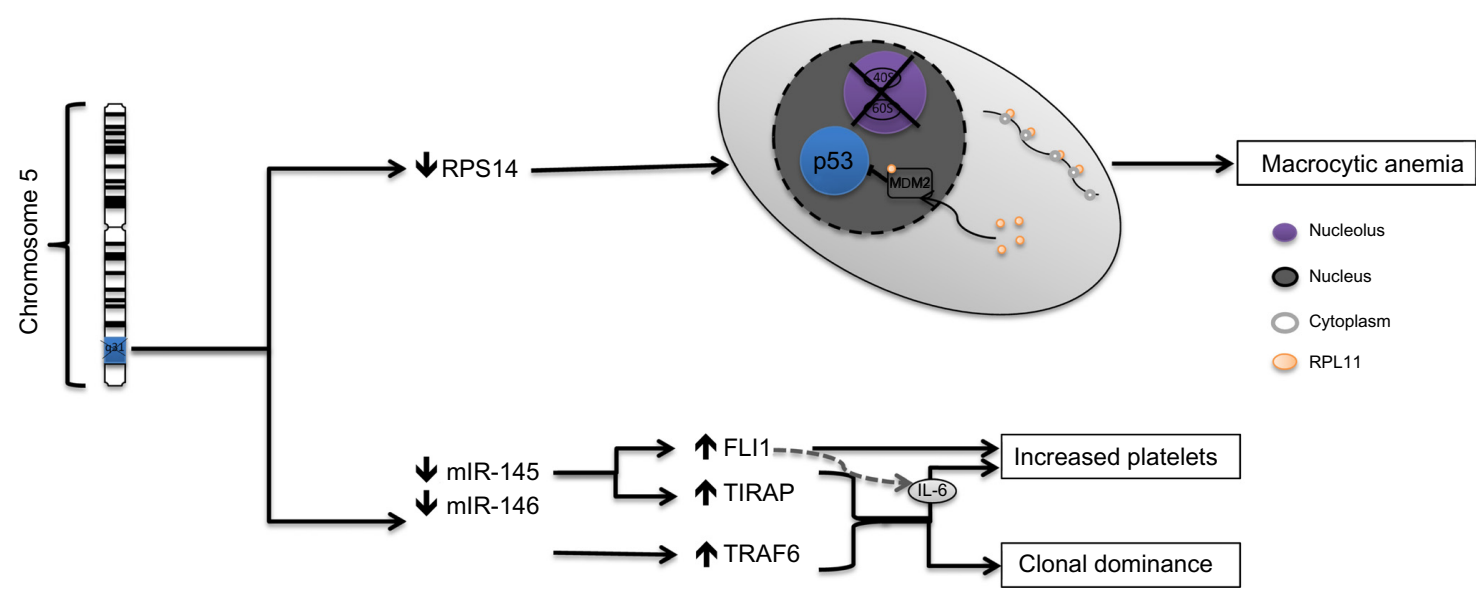

Figure I Molecular alterations associated with the $5 q$-syndrome.

Notes: Ribosomal haploinsufficiency leads to upregulation of RPLII which binds to MDM2 and prevent its binding to p53, leading to an increased in p53 expression. MDM2 is the central negative regulator of $p 53$, acting as E3 ubiquitin ligase toward $p 53$ leading to proteasome degradation of $p 53$. Haploinsufficiency of miRNA will lead to increased expression of TRAF6, TIRAP, FLII, and interleukin-6. TRAF6 and TIRAP contribute to clonal dominance. Interleukin-6 and FLII will contribute to enhanced megakaryopoiesis. ${ }^{34-37}$ Copyright $(C)$ 20II. Japanese Society of Hematology. Adapted with permission from Narla A, Hurst SN, Ebert BL. Ribosome defects in disorders of erythropoiesis. Int J Hematol. 201 I;93(2): I44-149..$^{34}$ Adapted from Starczynowski DT, Karsan A. Deregulation of innate immune signaling in myelodysplastic syndromes is associated with deletion of chromosome arm 5q. Cell Cycle. 2010;9(5):855-856. Copyright and all rights reserved. Material from this publication has been used with the permission of Landes Bioscience. ${ }^{37}$

\section{Haploinsufficiency of microRNA genes}

MicroRNAs (miRNAs) are small noncoding RNA molecules, and are important for inhibiting translation and destabilizing target protein encoding mRNA. Two miRNAs (miR145 and miR146 $\alpha$ ) are involved in downregulation of genes involved in regulation of the innate immune system..$^{32}$ The genes for both miRNAs are downregulated in CD34+ cells from del(5q) MDS patients compared with healthy controls. ${ }^{32,36}$ Haploinsufficiency of these miRNAs will result in upregulation of TIRAP, TRAF6, IRAK1, and IRAK2 (IL-1 receptor-associated kinase 1 and 2, respectively). ${ }^{36}$ TRAF6 upregulation will lead to increased production of IL-6 and activation of nuclear factor kappa beta. ${ }^{37}$ Increased IL-6 is thought to lead to abnormal megakaryocytes and the elevated platelet count seen in MDS with 5 q-syndrome. ${ }^{37}$ Activation of nuclear factor kappa beta is thought to lead to clonal dominance (Figure 1). Starczynowski et al showed that chimeric mouse BM, in which miR145 and miR146 $\alpha$ are reduced or TRAF6 is overexpressed, had characteristic megakaryocytic dysplasia, elevated platelets, and clonal dominance similar to what is seen in BM failure or AML. ${ }^{37}$

\section{Haploinsufficiency of tumor suppressor genes}

Haploinsufficiency in several tumor suppressor genes (Table 1) may contribute to the proliferative advantage of del(5q) clones and lead to hypercellular BM. Among the tumor suppressor genes lost is SPARC, which regulates extracellular interactions and has antiangiogenic, antiproliferative, and antiadhesive properties. ${ }^{38}$ Other haploinsufficient genes include EGR1, DIAPH1, and NPM-1 (Table 1). ${ }^{32}$

\section{Mechanism of action of lenalidomide}

Thalidomide has been historically used in lower-risk MDS, although its use has been limited due to its side effect profile. Limited clinical data have shown that its effect in $\operatorname{del}(5 q)$ MDS is similar to that in non-del(5q) MDS. ${ }^{39-43}$ Several in vitro and in vivo studies demonstrated the sensitivity of del(5q) cells to lenalidomide. ${ }^{32}$ Although the in vivo mechanisms of action of lenalidomide in MDS (particularly del(5q) MDS) are not completely understood, several studies suggest that lenalidomide most probably acts through karyotype-dependent pathways by its impact on haplodeficient genes ${ }^{32}$ and karyotype-independent pathways by its effect on erythroid differentiation genes, immune function, and angiogenesis (Figure 2 and Table 1). 22,32,34

\section{Effect of lenalidomide on haplodeficient genes and their pathways}

Wei et $a l^{44}$ demonstrated that lenalidomide is selectively cytotoxic to del $(5 q)$ cells as a result of its direct and indirect inhibition of the haplodeficient phosphatases (CDC25C and PP2A). ${ }^{32}$ PP2A dephosphorylates CDC25C, enabling mitotic entry. Lenalidomide directly inhibits CDC25C phosphatase and indirectly inhibits PP2A and CDC25A activity. This translates into a higher apoptotic response (G2 arrest) in cells with dual knockdown of CDC25C and 


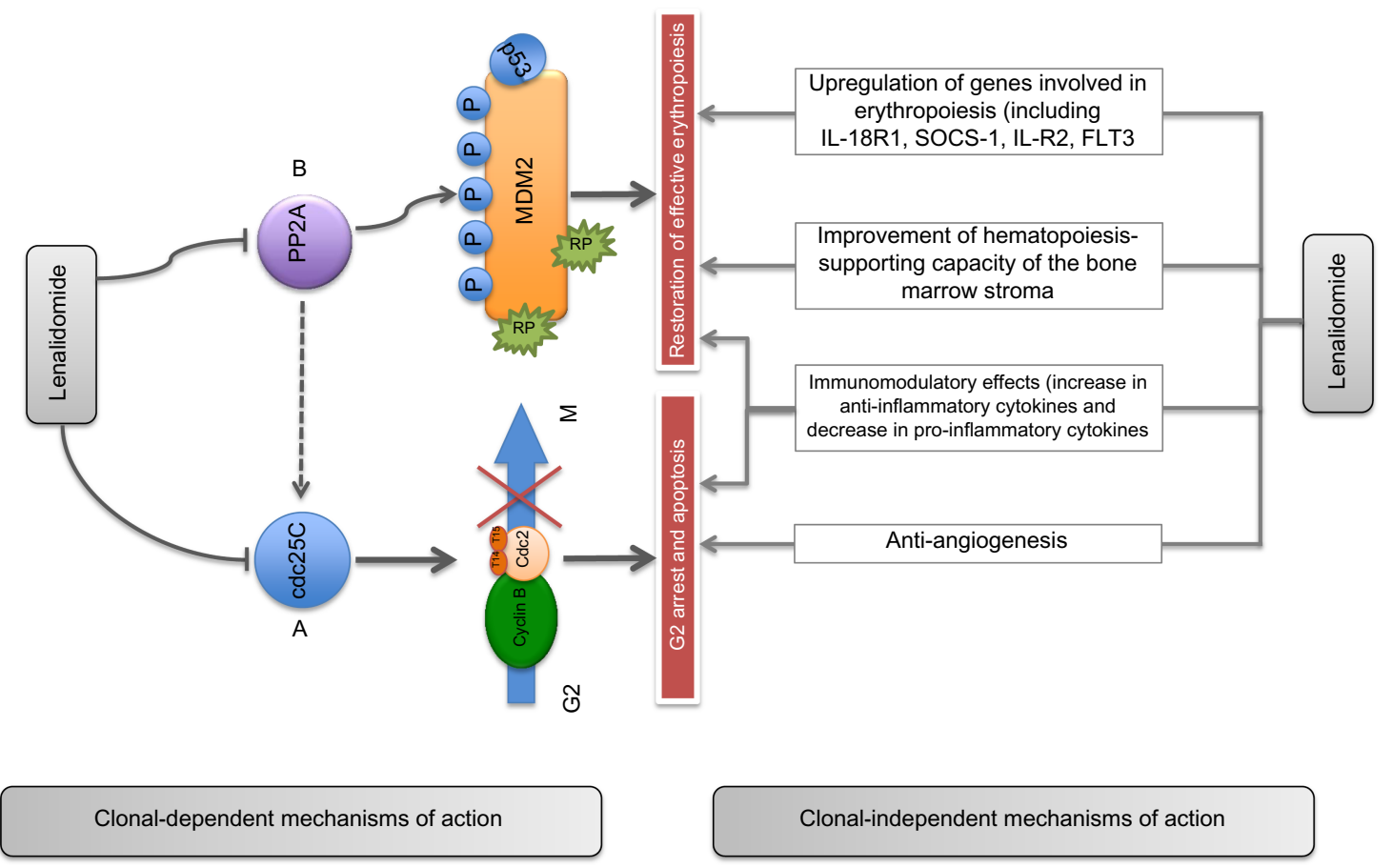

Figure 2 Suggested mechanism of action of lenalidomide del(5q) MDS.

Notes: The dual biological effect of lenalidomide (clonal eradication and promotion of erythropoiesis) is mediated by (A) clonal-dependent mechanisms which are augmented by clonal-independent mechanisms (B). Lenalidomide directly inhibits CDC25C resulting in G2/M arrest and contributing to clonal eradication. It indirectly inhibits PP2A leading to the accumulation of the stable hyperphosphorylated form of MDM2 despite its continued binding to free ribosomal proteins, leading to $\mathrm{p} 53$ degradation. Adapted from Duong $\mathrm{VH}$, Komrokji RS, List AF. Efficacy and safety of lenalidomide in patients with myelodysplastic syndrome with chromosome 5q deletion. Ther Adv Hematol. 20I2;3(2): I05-I I6. Copyright $(2) 2012$ by SAGE Publications. Reprinted by permission of SAGE.90

PP2Aco-mimicking haplodeficient cells. ${ }^{32}$ Lenalidomide can reverse the stabilization of p53 that results from haploinsufficiency in RPS14 and exerts dose-dependent inhibitory effects on $\mathrm{CDC} 25 \mathrm{C}$ and $\mathrm{PP}_{2} \mathrm{~A}^{44}$ (Figures 1 and 2). This in turn prevents PP2A from dephosphorylating MDM2. The treatment of PP2A $\alpha$-haplodeficient cells with lenalidomide results in concentration-dependent hyperphosphorylation of MDM2, abolishing its autoubiquitination. This will stabilize MDM2 and promote $\mathrm{p} 53$ degradation. ${ }^{44}$ Additionally, lenalidomide upregulates the expression of miRNA-143 and miRNA-145 and also upregulates SPARC expression. Increased SPARC expression normalizes the interaction of $\operatorname{del}(5 \mathrm{q})$ clones with the extracellular matrix. This might increase the apoptotic activity of lenalidomide in $\operatorname{del}(5 \mathrm{q})$ cells. $^{32}$

\section{Effect on BM function}

Lenalidomide improves BM function by different mechanisms. By reducing del(5q) clones, it helps accelerate the repopulation of BM by normal cells. In addition to helping decrease abnormal clones, lenalidomide can promote normal hematopoiesis by upregulating several genes important for erythroid differentiation and by improving the hematopoiesis-supporting capacity of the BM stroma (Figure 2). ${ }^{32,45}$ Lenalidomide was shown to increase red blood cell (RBC) production. ${ }^{46}$ Studies demonstrated that primary human CD34+ cells treated with lenalidomide had increased expression of several genes involved in erythropoiesis. Among the genes upregulated by lenalidomide alone or in combination with dexamethasone are FLT3, JAK2, and IL-1R2. These genes have important functions in erythropoiesis. Forced expression of the FLT3 gene confers a proliferative advantage with increasing erythroid differentiation. Increased expression of JAK2 increases the response to erythropoietin.

In addition to increasing the expression of genes important for erythropoiesis in non-del(5q) erythroid precursors, lenalidomide enhances erythropoietin signaling in these cells..$^{47,48}$ Inhibition of PP2A phosphatase in non-del $(5 q)$ erythroid precursors by lenalidomide leads to enhancement of erythropoietin receptor signaling by relieving CD45 repression of ligand-dependent signaling JAK2 and Lyn kinase-mediated STAT5 activation. ${ }^{47,48}$ This mechanism is thought to be secondary to rearrangements of lipid rafts resulting in incorporation of the erythropoietin receptor and its signaling intermediates such as Lyn kinase and STAT5 into raft domains and in translocation of their principal negative regulator (CD45 protein tyrosine phosphatase) into non-raft membrane fractions. ${ }^{47,48}$ 


\section{Effect on immune function and angiogenesis}

Altered cytokine production

The immunomodulatory activity of lenalidomide leads to inhibition of production of proinflammatory cytokines, namely IL-1, IL-6, IL-12, and tumor necrosis factor- $\alpha$, while also leading to upregulated production of anti-inflammatory cytokines, such as IL-10. ${ }^{49}$ Tumor necrosis factor-alpha is primarily produced by monocytes and macrophages and plays an important role in combating viral and bacterial infections. Its elevation is implicated in stem cell apoptosis and the ineffective hematopoiesis seen in MDS. ${ }^{50,51}$ Another proinflammatory cytokine decreased by lenalidomide is IL-6. This can help in reversal of the IL-6 upregulation that results from miRNA haploinsufficiency. ${ }^{36}$

\section{T-cell activation}

T-cell activation involves the presentation of antigen by antigen-presenting cells to the T-cell receptor. ${ }^{51} \mathrm{~A}$ secondary costimulatory interaction of the $\mathrm{B} 7$ molecule on antigenpresenting cells and CD28 on the T-cell surface augments the T-cell response and aids in T-cell proliferation, differentiation, and survival. ${ }^{51}$ Cereblon is a potential inhibitor of CD28 stimulation..$^{52}$ Lenalidomide, by suppressing cereblon, might increase functional T-cell activation through the CD28 pathway. ${ }^{52}$ Increased T-cell activation can lead to increased antileukemic immunosurveillance..$^{52}$ Alternatively, it may help in removing the suppressive immature cell population from the BM microenvironment, allowing for improved erythropoiesis. $^{52}$

\section{Antiangiogenic activity}

Immunomodulatory agents like thalidomide and lenalidomide have been shown to significantly decrease the expression of the angiogenic factors vascular endothelial growth factor and IL-6. ${ }^{53,54}$ In MDS patients, blast cells overexpress vascular endothelial growth factor receptors, an observation correlated with lower remission rates. ${ }^{55}$ The antiangiogenic activity of lenalidomide results in reduced BM vascularity in patients with del $(5 q)$ MDS. Reduced BM vascularity in del(5q) has been associated with a clinical response and its loss was found to predict disease progression. . $^{32,34,56}$

\section{Clinical efficacy}

Ineffective hematopoiesis is one of the salient features of MDS. Prior to lenalidomide, many MDS patients with anemia secondary to ineffective erythropoiesis were only managed with blood transfusion and/or ESAs, with variable symptomatic responses. The first trial to evaluate the safety and hematological activity of lenalidomide was MDS- $001^{57}$ (Table 2). In this single-center Phase I/II trial, 43 patients with MDS (mostly lower-risk) and symptomatic anemia (defined as hemoglobin $<10 \mathrm{~g} / \mathrm{dL}$ or transfusion dependence requiring at least 4 units of red cells within 8 weeks of enrollment) were enrolled. All patients were refractory to ESAs or had high endogenous erythropoietin levels $(>500 \mathrm{mIU} / \mathrm{mL})$, and 12 patients had $\operatorname{del}(5 \mathrm{q})$. Patients with neutropenia $\left(<500 / \mathrm{mm}^{3}\right)$ or thrombocytopenia (platelet count $<10,000 / \mathrm{mm}^{3}$ ) were excluded. The clinical efficacy and safety of lenalidomide at doses of 25 or $10 \mathrm{mg}$ daily or $10 \mathrm{mg}$ daily for 21 days of every 28 -day cycle were assessed. The hematological overall response rate was $56 \%$. RBC transfusion independence (RBC-TI) was achieved in 20/32 patients who were transfusion-dependent. Patients with del(5q) had an overall response rate of $83 \%$ versus $53 \%$ in patients with non-del $(5 q)$ and $12 \%$ in patients with other karyotypic abnormalities. The cytogenetic response also correlated significantly with the hematological response. ${ }^{57}$

\section{Clinical efficacy in lower risk MDS with del(5q)}

The efficacy of lenalidomide in MDS with del(5q) was further investigated in MDS-003 and MDS-004 (Table 2). ${ }^{45,58}$ Both trials included low-risk and intermediate- 1 risk IPSS patients and excluded patients with severe neutropenia $\left(<500 / \mathrm{mm}^{3}\right)$ or thrombocytopenia (platelet count $<50 \times 10^{3} / \mathrm{mm}^{3}$ in MDS- 003 and platelet count $<25 \times 10^{9} / \mathrm{L}$ in MDS-004). MDS-003 was a single-arm study that included 148 patients requiring transfusion of at least 2 units of blood in the 8 weeks prior to enrollment. ${ }^{45}$ In total, 111 patients had isolated del(5q) while 37 had del $(5 q)$ with additional chromosomal abnormalities. At 24 weeks, the overall response rate was $76 \%$. Among the responders, 99 (67\%) achieved RBC-TI. The median time to RBC-TI was 4.6 weeks. The median hemoglobin increase in patients achieving RBC-TI was $5.4 \mathrm{~g} / \mathrm{dL}$, and the median duration of RBC-TI was 2.2 (range 1.5-2.9) years. ${ }^{59}$ Complete cytogenetic response, assessed at week 24 of treatment, was reached in 38/85 patients (45\%), while 24/85 (28\%) had a partial cytogenetic response, defined as a more than $50 \%$ reduction in abnormal metaphases. ${ }^{45}$ Side effects are summarized in Table 2, with myelosuppression being the most prominent. Sixty-two percent of grade 3-4 myelosuppression occurred within the first 8 weeks of treatment. Dose reductions were required in $84 \%$ of patients. Thirty patients $(20 \%)$ discontinued the drug due to adverse events. 


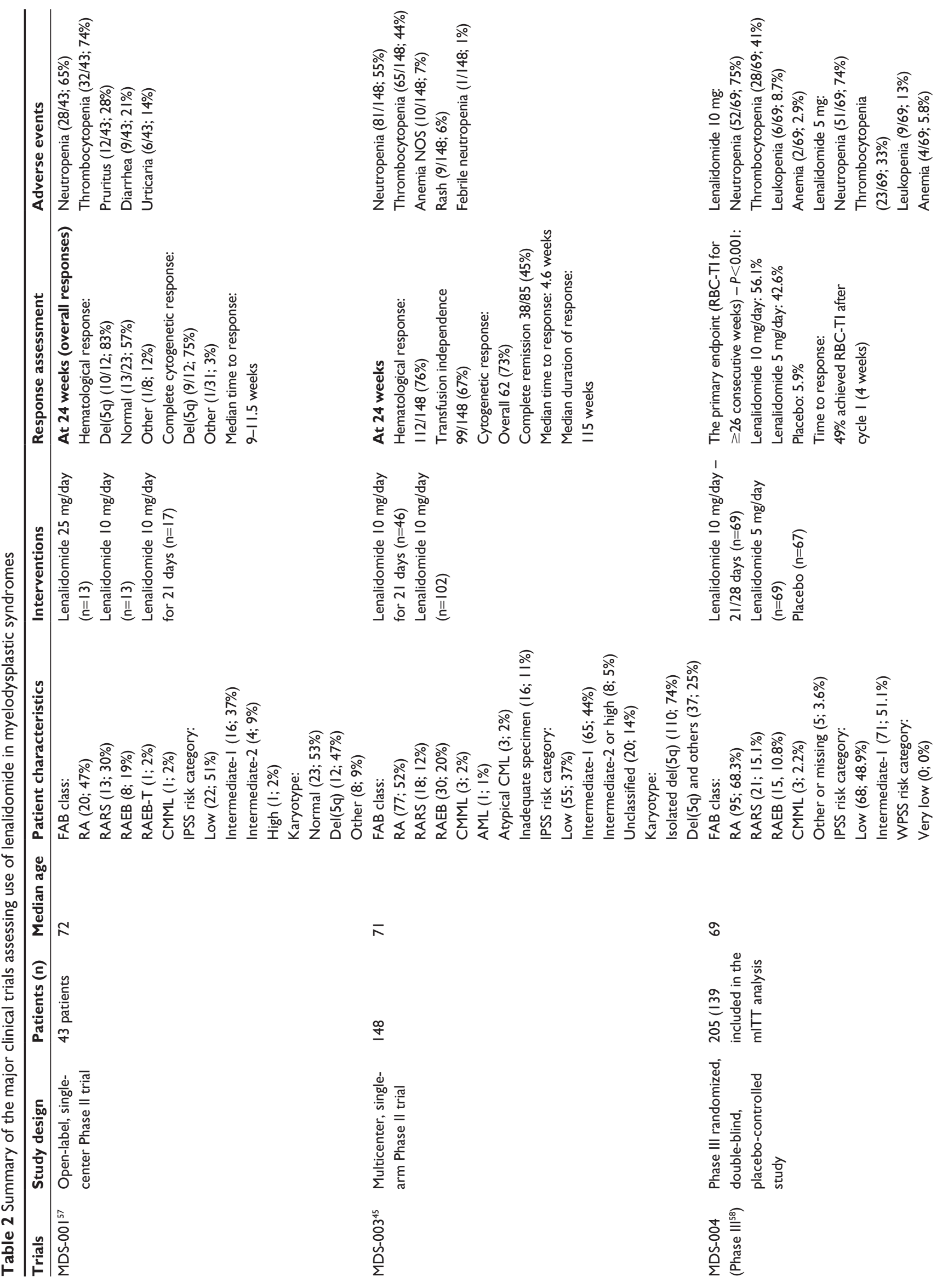



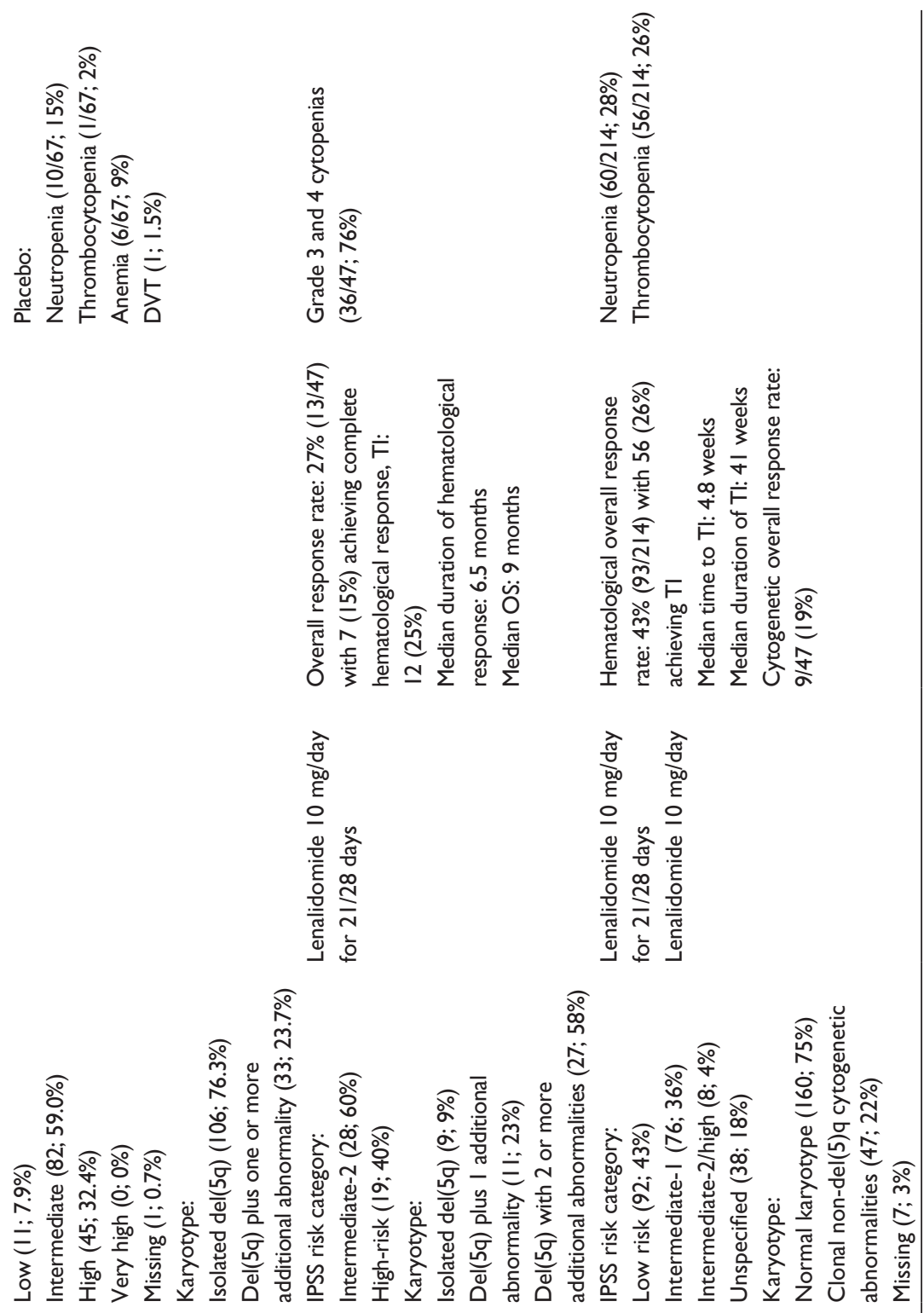

a

$\sin$

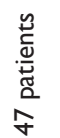

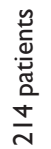

$\frac{\bar{x}}{\frac{2}{5}}$
$=$
$\bar{y}$
$\frac{y}{2}$
$\frac{\bar{\alpha}}{2}$

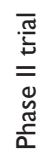

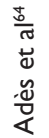

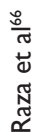

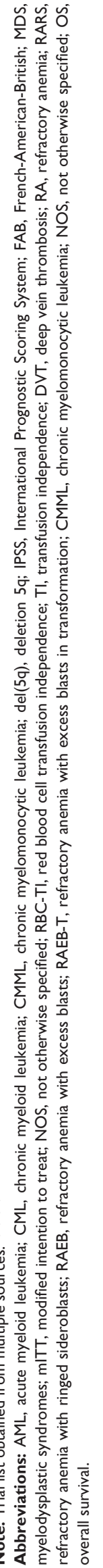


The results of the MDS-003 trial were validated further in the randomized, double-blind, placebo-controlled MDS004 trial. ${ }^{58}$ MDS-004 randomized 205 patients with lowerrisk IPSS, transfusion-dependent MDS, and del(5q) with or without additional cytogenetic abnormalities to receive placebo daily, lenalidomide $5 \mathrm{mg}$ daily, or lenalidomide 10 $\mathrm{mg}$ daily for 21 days of 28-day cycles. All patients were transfusion-dependent. RBC-TI for $\geq 26$ weeks was $56.1 \%$ with lenalidomide $10 \mathrm{mg}, 42.6 \%$ with lenalidomide $5 \mathrm{mg}$, and $5.9 \%$ with placebo. ${ }^{58}$ The cytogenetic response rate was $50 \%$ in the $10 \mathrm{mg}$ group and $25 \%$ in $5 \mathrm{mg}$ group. Again, myelosuppression was a major side effect reported in MDS004 , with $55.1 \%$ of patients in the $10 \mathrm{mg}$ group and $52.2 \%$ of those in the $5 \mathrm{mg}$ group requiring dose reduction. The drug was discontinued in $8.7 \%$ and $17.4 \%$ of patients in the 10 $\mathrm{mg}$ and $5 \mathrm{mg}$ groups, respectively.

\section{Quality of life data in lower risk del(5q) MDS}

Quality of life was not reported in MDS-003, but was reported in MDS-004 and in a study reported by Oliva et al. ${ }^{60}$ In the latter study, patients who responded to lenalidomide experienced progressive improvement in their quality of life in the first 24 weeks of therapy. A health-related quality of life outcome analysis from the MDS-004 study demonstrated that the hematological improvements obtained with lenalidomide were associated with improvement in health-related quality of life in both the short term (12 weeks) and the long term (48 weeks).

\section{Progression and survival outcome in lower-risk MDS with del(5q)}

New chromosomal abnormalities were observed in a subset of patients treated with lenalidomide (24/148 patients in MDS-003). This raised concerns regarding a potential increase in the incidence of clonal evolution and progression to AML. The results of a long-term follow-up analysis of 42 patients with low-risk or intermediate-risk del(5q) MDS treated with lenalidomide have been published. ${ }^{61}$ After a median followup of 40 months, $36 \%$ of patients progressed to AML, and most $(87 \%)$ acquired additional chromosome aberrations. Responders have a decreased risk of progression. At 5 years, the cumulative incidence of progression to AML for patients with a cytogenetic response was $21 \%$ compared with $60 \%$ for nonresponders. ${ }^{61}$ This prompted several groups to perform historical comparisons of the rate of leukemic progression between low-risk del $(5 q)$ MDS patients treated before the lenalidomide era and lenalidomide-treated patients. Comparative analysis by the Groupe Francophone des Myélodysplasies found no significant difference in progression of AML between the lenalidomide-treated group and a matched control cohort. ${ }^{62}$ In this comparative study, 71 lenalidomide-treated patients were matched with 71 patients from a historical control cohort based on propensity score. The control cohort was treated with erythropoietin or thalidomide. The median follow-up from diagnosis for the lenalidomide-treated group was 4 years and that for the control cohort was 6.5 years. There was no statistically significant difference in the 4-year estimated cumulative incidence of AML from diagnosis between the two groups, with a hazard ratio of 0.87 (95\% confidence interval $0.27-2.82 ; P=0.82$ ). The 4 -year estimated cumulative incidence in the lenalidomide-treated group was $9 \%$ and $15.7 \%$ in the matched controls. ${ }^{62}$

Results from the comparative analysis reported by Kuendgen et al support the above results from Groupe Francophone des Myélodysplasies. ${ }^{63}$ In the study by Kuendgen et al, long-term clinical outcomes in $\operatorname{del}(5 q)$ MDS patients treated with lenalidomide in the MDS-003 and MDS-004 trials were compared with a cohort of untreated low-risk or intermediate- 1 risk MDS patients with $\operatorname{del}(5 q)$ not treated with lenalidomide derived from nine MDS registries. The cumulative incidence of progression to AML was 6.9\% and $22.8 \%$ at 2 and 5 years, respectively, for the lenalidomide-treated group, and $12.1 \%$ and $19.9 \%$ at 2 and 5 years, respectively, for the group not treated with lenalidomide. Treatment with lenalidomide was not associated with an increased risk of AML progression (hazard ratio $0.9 ; P=0.930$ ). The median overall survival was higher (5.2 years, 95\% confidence interval 4.5-5.9) in the treated group versus 3.8 years $(95 \%$ confidence interval 2.9-4.8) in nontreated patients. ${ }^{63}$

Further data about survival and risk of AML progression came from the MDS-003 study investigators, who reported the long-term outcomes of overall survival and AML progression in patients enrolled in the MDS-003 trial. ${ }^{59}$ After a median follow-up of 3.2 years, median overall survival was 3.3 years and the cumulative one-year and 5-year overall survival rates were $84.2 \%$ and $30.4 \%$, respectively. Median overall survival was longer in patients with isolated $\operatorname{del}(5 q)$ than in patients with $\operatorname{del}(5 q)$ and additional cytogenetic abnormalities (3.9 years versus 2.7 years, respectively). The mortality rates were lower in patients with RBC-TI for at least 8 weeks compared with nonresponders (58.8\% versus $86.3 \%) .{ }^{59}$ Patients with RBC-TI for at least 8 weeks had better overall survival rates at one and 5 years than nonresponders $(96.8 \%$ and $41.1 \%$ versus $81.6 \%$ and $14 \%$ respectively). Cytogenetic response was also associated with a lower mortality rate and better 
overall survival. Median overall survival was 4.9 years in cytogenetic responders versus 3.1 years in nonresponders. ${ }^{59}$ When compared with historical controls (MDS patients who received best supportive care), the median overall survival was around one year longer in responders. Patients who achieved RBC-TI for at least 26 weeks and a cytogenetic response had the lowest incidence of AML progression (14\%), while those who achieved neither had the highest incidence of AML progression (52.9\%). ${ }^{59}$

Taken together, these observations suggest that hematological and cytogenetic responses in IPSS lower-risk $\operatorname{del}(5 q)$ anemic MDS patients treated with lenalidomide are possibly associated with improved overall survival and reduced risk of AML progression, but further data are needed. These results are consistent with emerging data suggesting that AML progression rates in patients treated with lenalidomide are probably not drug-related but are associated with additional risk factors as discussed later in the section "Predictors and prognosticators beyond the $\operatorname{del}(5 q)$ and IPSS". MDS-003 and MDS-004 are the main studies supporting the use of lenalidomide in the treatment of IPSS lower-risk del(5q) MDS patients who are RBC transfusion-dependent.

\section{Clinical efficacy in higher-risk MDS with del(5q)}

The overall response rate to lenalidomide $10-30 \mathrm{mg}$ as a single agent in patients who have IPSS higher-risk MDS with del(5q) is lower than that seen in IPSS low-to-intermediate-1 risk MDS with $\operatorname{del}(5 q) .{ }^{1}$ The overall response rate in the high-risk population was around $25 \%-30 \%$ and did not differ between patients with $\operatorname{del}(5 q)$ and non-del $(5 q) .{ }^{1}$ In addition, the response was not durable. ${ }^{1}$ In a Phase II trial, ${ }^{64} 47$ patients with higher-risk $\operatorname{del}(5 q)$ MDS received lenalidomide $10 \mathrm{mg}$ /day, and the overall response rate according to the International Working Group 2006 criteria was $27 \%$ (13/47). Most of the complete hematological remissions were seen in patients with isolated del $(5 q)$. The median duration of response was 6.5 months. ${ }^{64}$

Strategies have been employed to increase responses in this population, including combining lenalidomide with other agents (see "Combination strategies" section.) or increasing the dose of lenalidomide. Another Phase II trial ${ }^{65}$ investigated the role of higher doses of lenalidomide in patients who have higher-risk MDS with del(5q). Twenty-nine patients were enrolled in this study (16 with AML, 12 with intermediate-2 or high-risk MDS) who were not candidates for regular induction treatment. The lenalidomide dose was escalated from $10 \mathrm{mg}$ to a target dose of $30 \mathrm{mg}$ at week 10 . Ten patients completed 16 weeks of treatment, and five of these patients achieved a major cytogenetic response. The overall response rate in MDS patients was 36\% (4/11). Despite the small size of the MDS patient sample, this study showed that a group of patients with high-risk MDS and $\operatorname{del}(5 q)$ could tolerate and respond to higher doses of lenalidomide. ${ }^{65}$

\section{Clinical efficacy in non-del(5q) MDS}

MDS-001 showed that the overall response rate in anemic patients with non-del $(5 q)$ lower-risk MDS is lower than that in $\operatorname{del}(5 q)$. However, the trial demonstrated that a group of non-del(5q) MDS patients did respond to lenalidomide. Several studies were conducted to assess the efficacy of lenalidomide in non-del(5q) MDS. The reported hematological improvement in these studies, with patient samples that included lower-risk MDS of unselected or non-del(5q) karyotype, ranged from $26 \%$ to $64 \%$, with a median duration of response of 12-20 months. ${ }^{1}$

The largest study assessing the efficacy of lenalidomide in non-del $(5 q)$ MDS was conducted by Raza et al. ${ }^{66}$ In this Phase II study, the efficacy of lenalidomide $10 \mathrm{mg}$ daily for 21 of 28 days was assessed in 214 patients with low-risk or intermediate-1 risk non-del(5q) MDS who were RBC transfusion-dependent and receiving at least 2 units of $\mathrm{RBC}$ within 8 weeks of initiation of treatment. The overall response rate was $43 \%$, with $26 \%$ of patients becoming RBC-TI. The median time to RBC-TI was 4.8 weeks. The median duration of RBC-TI was 41 weeks. ${ }^{12,66}$

Lenalidomide has not been approved by the US Food and Drug Administration for use in anemic patients with non$\operatorname{del}(5 q) \mathrm{MDS}$, although it is commonly used after failure of ESAs or for those with a high baseline serum erythropoietin level. Ongoing studies are trying to identify strategies that increase the response rate, such as using it in combination with other agents, in addition to trying to predict which non$\operatorname{del}(5 q)$ patients will have the best response.

\section{Predictors and prognosticators beyond the $\operatorname{del}(\mathbf{5 q})$ and IPSS}

Within the del(5q) MDS patient population, clinical outcomes and response to lenalidomide have been negatively affected by certain baseline clinical characteristics, such as higher transfusion burden, anemia, lower platelet count, male sex, additional chromosomal abnormalities, and a higher percentage of BM blasts. ${ }^{63}$ To date, no clinical or molecular factors have consistently predicted the response to lenalidomide in patients with $\operatorname{del}(5 q)$ or identified subsets of non-del( $5 q)$ or high-risk del(5q) that benefit from lenalidomide. With improvements in the use of 
next-generation sequencing platforms, we are learning more about the abundance of these mutations in MDS. Ebert et al analyzed the pretreatment gene expression patterns in patients from MDS-002 (low-risk MDS patients without $\operatorname{del}(5 \mathrm{q}),{ }^{67}$ and identified a set of 47 genes that were more highly expressed in nonresponders than responders. These genes are specific to terminal erythroid differentiation. This gene signature correctly predicted the response to lenalidomide in 9/11 (82\%) samples from low-risk patients without del(5q). This gene signature has yet to be validated in a larger series. A 29-gene expression profile signature has been reported to be a predictor of hematologic response in non-del $(5 q)$ lower-risk MDS patients treated with lenalidomide alone or combined with erythropoietin-beta. ${ }^{68}$

In another study, ten (18\%) of 55 patients having lowrisk or intermediate- 1 risk MDS with $\operatorname{del}(5 q)$ were found to harbor TP53 mutations at diagnosis. ${ }^{69}$ The rate of progression to AML was $50 \%$ in the mutated group compared with $16 \%$ in the nonmutated group, and the response rate was $0 \%$ in the mutated group compared with $50 \%$ in the nonmutated group. ${ }^{69,70}$ Mallo et al utilized conventional G-banding cytogenetics, single nucleotide polymorphism assays, and gene sequencing to identify additional molecular markers that could predict the response to lenalidomide in 52 patients with $\operatorname{del}(5 \mathrm{q}) \cdot{ }^{71}$ TP53 mutations were associated with an absence of a hematologic or complete cytogenetic response. Otherwise, this study did not show significant genomic differences between lenalidomide responders and nonresponders. ${ }^{71}$ These data highlight the clinical significance of TP53 mutations in the treatment of patients with $\operatorname{del}(5 q)$ and low-risk IPSS categorization. As discussed in the "Combination strategies" section patients with $\operatorname{del}(5 \mathrm{q})$ MDS and mutated TP53 might benefit from combination or more aggressive treatment.

Other mutations occur in patients with del(5q). It has been reported that $40 \%$ of patients with 5 q-syndrome harbor at least one gene mutation. ${ }^{72}$ Elucidation of the clinical significance of these additional mutations requires further investigation. In addition to TP53, other biomarkers that may predict the response to lenalidomide were evaluated in several relatively small studies. Sugimoto et al explored the relationship between molecular features and the clinical response to lenalidomide in patients without $\operatorname{del}(5 q) \cdot{ }^{73}$ This study demonstrated that normal karyotype and gain of chromosome 8 material were predictive of response to lenalidomide. Wu et al showed that lower RPS14 levels in low-risk MDS patients without $\operatorname{del}(5 \mathrm{q})$ are a good prognostic marker and can potentially predict a good response to lenalidomide. ${ }^{74}$ Specific cereblon polymorphisms have been associated with a hematological response to lenalidomide and may potentially serve as a predictive marker if well validated in future studies. ${ }^{68,75}$

As discussed, lenalidomide can activate T-cells by increasing CD28 activation. This may translate into increased antileukemic immunosurveillance. ${ }^{52}$ Epling-Burnette et al demonstrated that a higher percentage of CD28negative T-cells is associated with hematological failure of lenalidomide in non-del(5q) MDS. ${ }^{52}$ Thus, CD28 expression and signaling may serve as a potential predictor of hematologic response to lenalidomide in non-del(5q) MDS. ${ }^{52}$

\section{Mechanisms of resistance}

The phenotypic heterogeneity that characterizes del(5q) MDS is in part a reflection of additional genetic and karyotypic abnormalities beyond the $5 \mathrm{q}$ segment deletion that ultimately leads to a poorer response to lenalidomide. Beyond genetic and karyotypic abnormalities, resistance to lenalidomide is mediated by changes in several haplodeficient pathways leading to p53 accumulation, resulting in loss of erythropoietic response. ${ }^{11}$ In vitro studies suggest that haploinsufficiency of CDC25C and PP2A in $\operatorname{del}(5 q)$ confers sensitivity to lenalidomide, and its overexpression might confer resistance. Wei et al demonstrated that forced overexpression of PP2A in $\operatorname{del}(5 q)$ cells promotes drug resistance. ${ }^{44}$ This is potentially clinically relevant. Studying sequential BM specimens from lenalidomide-treated patients, cellular expression of PP2A declined at the time of response to lenalidomide treatment, and significantly increased at the time of treatment failure. Overexpression of $\mathrm{PP} 2 \mathrm{~A}$ restores $\mathrm{p} 53$ expression in erythropoietic cells and leads to treatment failure. ${ }^{44}$

Given the central role of p53 in hypoplastic anemia, investigational strategies targeting p53 expression have been evaluated. The efficacy of cenersen, an antisense RNA that cleaves mRNA and effectively downregulates p53 expression, has been studied in overcoming resistance to lenalidomide. In vitro, cenersen suppressed p53 expression in del(5q) MDS. This was associated with a proportional increase in erythroid response without $\operatorname{del}(5 \mathrm{q})$ clonal suppression. ${ }^{11,76}$ Further discussion about the clinical role and application of p53 suppression is discussed in more detail in the "Combination strategies" section.

In a small study that included seven patients who achieved transfusion independence on lenalidomide, Tehranchi et al demonstrated that lenalidomide was effective in eradicating the majority of $\operatorname{del}(5 q)$ clones in responders. ${ }^{77}$ However, in 
all seven patients, even those with a complete response, there was evidence of selective persistence of a CD34+, CD38-/ low, and CD90+ resistant clone. This clone may persist in the BM because of its quiescent state (G0) and/or its high expression of multiple drug resistance genes. This resistant clone might explain why around $50 \%$ of responders relapsed despite lenalidomide treatment. ${ }^{77}$ Validating these results in larger cohorts may allow for better monitoring and targeting of this resistant clone.

\section{Combination strategies}

Several strategies are under evaluation to increase the response to lenalidomide, broaden its usage beyond the current approved indications, and overcome resistance. Lenalidomide has been combined with growth factors, AML-like chemotherapy, azacitidine, and other new agents. Komrokji et al evaluated hematologic response rates to lenalidomide monotherapy and combined treatment with recombinant erythropoietin-alpha. ${ }^{78}$ Thirty-nine low-risk or intermediate-1 risk patients with symptomatic anemia or transfusion dependence were enrolled in this Phase II trial. The majority were non-del $(5 q)$ patients $(n=32)$. The patients were started on monotherapy with lenalidomide (10 or $15 \mathrm{mg}$ daily). After 16 weeks of treatment with lenalidomide, nonresponders and relapsing patients were offered combination therapy with lenalidomide and recombinant erythropoietinalpha. Adding erythropoietin increased the response rate in both $\operatorname{del}(5 q)$ and non-del $(5 q)$ by a total of $25 \%$. A Phase III trial is currently being conducted to validate these results.

Combination therapy was not associated with increased adverse events, including venous thromboembolism (VTE). ${ }^{78}$ Another Phase II study supported the role of combination therapy. ${ }^{68}$ In this study, transfusion-dependent, low risk non-del(5q) MDS patients resistant to ESA or relapsed were randomized to lenalidomide alone or lenalidomide plus erythropoietin-beta. The lenalidomide dose was $10 \mathrm{mg} /$ day for $21 / 28$ days and the erythropoietin-beta dose was $60,000 \mathrm{U} /$ week. After four cycles of therapy, patients in the combination arm achieved better hematologic improvement, ie, $52.0 \%(26 / 50)$ versus $30.6 \%$ (14/49) in the lenalidomide group. RBC-TI was also higher in the combination arm, at 16 patients $(32 \%)$ versus nine $(18.4 \%)$ in the lenalidomide $\mathrm{arm}$. Side effects were similar in the two arms, with no increase in deep vein thrombosis in the combination arm. The authors concluded that combination treatment significantly increased the erythroid response rate in lower-risk non-del(5q) MDS patients with anemia resistant to ESA alone. ${ }^{68}$

Another Phase II study evaluated the safety and efficacy of combining romiplostim with lenalidomide to decrease the incidence of treatment-related thrombocytopenia in patients with low-risk or intermediate-1 risk MDS. ${ }^{79}$ The authors reported that this combination decreased the rate of clinically significant thrombocytopenic events and in turn decreased the frequency of lenalidomide dose reductions or delays ${ }^{71}$ The main concern about using romiplostim in MDS is the increased risk of transformation to AML, especially in high-risk groups, as suggested by early Phase II trials. ${ }^{79}$ Only results from large Phase III trials can adequately assess this risk, especially in patients with low-risk disease in whom lenalidomide is used for the most part at this time. ${ }^{80}$

Several Phase I and II studies examined the efficacy and safety of combining azacitidine and lenalidomide. ${ }^{81-83}$ Lenalidomide and azacitidine could potentially have synergistic effects. Azacitidine can potentially increase the response rate in del $(5 q)$ patients with TP53 mutations, while lenalidomide can potentially increase the response rate in patients with complex karyotypes including del $(5 \mathrm{q}) \cdot{ }^{84} \mathrm{~A}$ landmark Phase II trial by Sekeres et al explored the efficacy of a concurrent combination of lenalidomide and azacitidine.$^{81}$ The study included 36 patients, the majority ( $87 \%$ ) of whom had intermediate- 2 and high-risk IPSS disease, and only two patients had del(5q). The overall response rate was $72 \%$ and the complete response rate was $44 \%$. The median time to response was 3.7 months and the median duration of response in patients with a complete response was $17+$ months. This is compared with the overall response rate of $49 \%$ and the complete response rate of $17 \%$ with azacitidine alone. Median overall survival was 13.6 months. This is shorter than the median overall survival in the AZA-001 trial, which was 24.5 months. ${ }^{85}$ This could be due to a shorter median follow-up (11.5 months versus 21.1 months). The median neutrophil and platelet decrease was $35 \%$ and $15 \%$, respectively. Grade 3 and 4 nonhematologic toxicities were comparable with those seen with each medication individually. ${ }^{81}$ This combination is the subject of an ongoing randomized Phase III US Intergroup study.

In a multicenter Phase I trial, 19 patients with higher-risk MDS/AML and del $(5 q)$ were enrolled ${ }^{82}$ to receive a sequential combination regimen of lenalidomide and azacitidine. In partial responders, induction therapy was continued for up to eight cycles. Patients who achieved a complete BM response after two cycles of induction were shifted to maintenance therapy aiming at decreasing the hematologic toxicity. The overall response rate was $26 \%$ in all patients, and was $44 \%$ in previously untreated patients. The median duration of hematologic and cytogenetic response was 2.3 months and 3.2 months, respectively. These responses, although shortlived, were achieved in a study population rich in the p53 
mutation (11/17). This sequential combination resulted in a TP53 mutant clone decline and disappearance in one patient, and in decline followed by re-emergence in another patient. ${ }^{82}$ Re-emergence preceded relapse. Although the number is small, these effects on TP53 mutated clonal cells are significant since they have not been reported with lenalidomide alone. ${ }^{82}$ The authors of this study attributed the lower overall response rate when compared with the overall response rate seen in the study reported by Sekeres et al to the higher percentage of complex karyotypes as well as the higher proportion of patients with TP53 mutations in their cohort. ${ }^{81}$

Figure 3 summarizes the treatment scheme for some of the clinical trials using a combination of azacitidine and lenalidomide. The verdict is still out regarding the best regimen, ie, concurrent versus sequential, as well as the best maintenance strategy. ${ }^{23,86}$ So far, Phase I and Phase II studies suggest that combining azacitidine and lenalidomide is generally well tolerated, and can potentially lead to a better and faster overall response rate. However, it may be associated with more neutropenia and thrombocytopenia, and some of the responses were short-lived. Although the mechanisms of action for lenalidomide and azacitidine are different and can be synergistic, their cytoreductive potential is overlapping. Therefore, the search for compounds that act synergistically with lenalidomide without overlapping cytotoxic potential is ongoing.

Ezatiostat is potentially one of these compounds. Ezatiostat hydrochloride is a glutathione analog that can reversibly inhibit glutathione-S transferase P1-1, leading to activation of JNK and subsequent growth and maturation of hematopoietic progenitors. ${ }^{87}$ It has shown in vivo and in vitro activity in improving cytopenias in $\mathrm{MDS} .{ }^{87}$ Its use with lenalidomide is very appealing because, unlike many of the other combinations, it does not have a myelosuppressive effect and the response rate to ezatiostat was higher in patients previously treated with lenalidomide. ${ }^{87}$ Raza et al demonstrated the safety of combining ezatiostat $1,000 \mathrm{mg}$ twice daily with lenalidomide $10 \mathrm{mg}(21 / 28) .{ }^{87}$ Efficacy data are encouraging since the combination showed multilineage hematologic improvements even in some patients who progressed on lenalidomide. The combination is now being evaluated in Phase II studies. ${ }^{87}$

Given the role of p53 in the hypoplastic anemia of $\operatorname{del}(5 q)$ MDS and its potential role in drug resistance, a p53-targeted strategy to overcome resistance was explored in a proof-of-principle pilot study by Caceres et al. ${ }^{76}$ In this study, eight lenalidomide-resistant patients were treated with lenalidomide and dexamethasone. Dexamethasone was chosen because it is a transcriptional antagonist of p53. All patients had del(5q) MDS with an IPSS score of 1 . Initially, all patients responded to lenalidomide by becoming transfusion-independent. However, all developed resistance and became transfusion-dependent again. A weekly dose of $20 \mathrm{mg}$ of dexamethasone was combined with the usual dose of lenalidomide. Five patients achieved transfusion independence, with durations of response ranging from 4.4 months to 15 months. ${ }^{76}$ p53-targeted strategies should employ treatment strategies that lead to nonsustained suppression of p53, such as weekly dexamethasone, since sustained suppression may significantly increase the risk of neoplasia.

\section{Real-life use of lenalidomide for treatment of MDS}

The "real-life" patterns of use and clinical efficacy of lenalidomide in management of MDS in the USA are not clear.

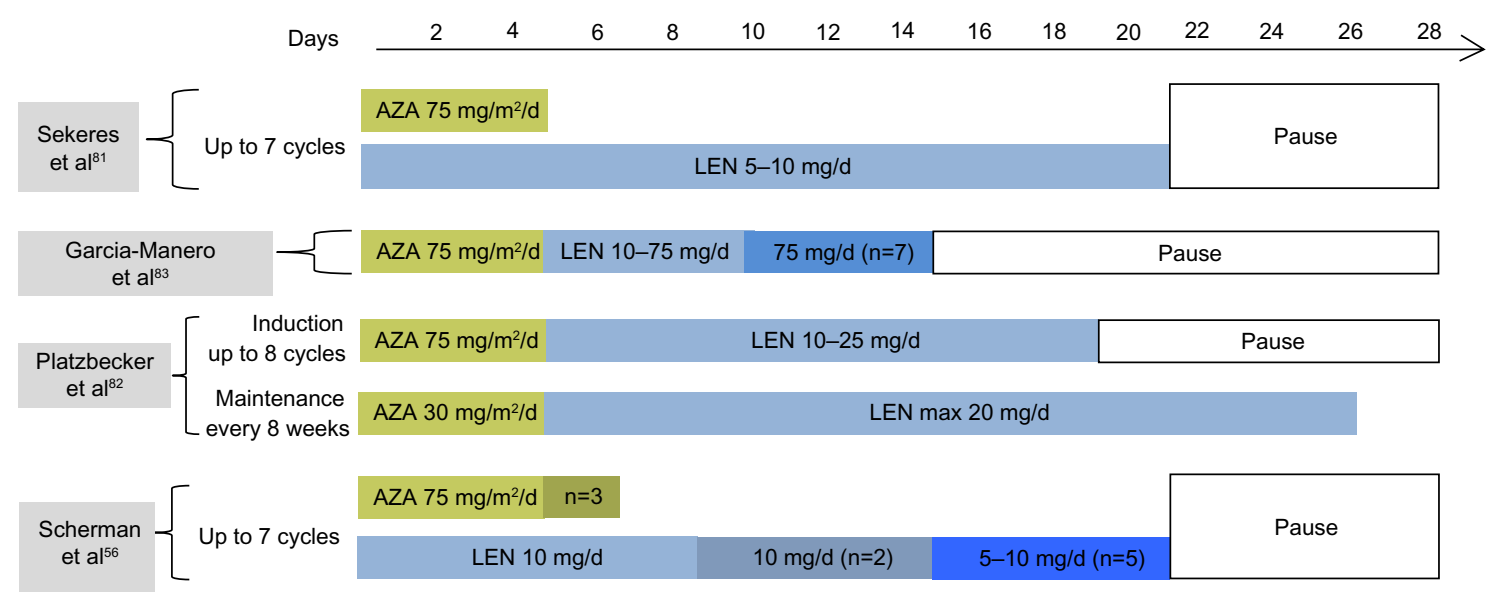

Figure 3 Treatment scheme of Phase I and II clinical trials using combinations of azacitidine and lenalidomide in patients with myelodysplastic syndrome or acute myeloid leukemia.

Abbreviations: LEN, lenalidomide; AZA, azacitidine; d, day. 
Zeidan et al published the first report of lenalidomide use in a large cohort of Medicare-enrolled patients with MDS. ${ }^{88}$ The authors identified 23,855 MDS patients enrolled in the Medicare program in the USA using International Classification of Diseases 9 codes between 2006 and 2008 and followed the patients until the end of the study or death. Claims-based data were used to determine MDS subtype, lenalidomide dose, time to initiation and duration of therapy, use of other MDS therapies, comorbidities, and RBC transfusion frequency. The researchers defined RBC transfusion status using weekly measures in a rolling 8-week period to classify patients into three separate categories based on their transfusion needs: those who received RBC transfusions in separate 2 weeks were classified as transfusion dependent, those who received one transfusion as transfusion users, and those who did not receive any transfusions as transfusion-independent. ${ }^{88}$

In total, $753 \mathrm{MDS}$ patients (3.2\%) received lenalidomide. Interestingly, most of these patients did not have a coding diagnosis of $\operatorname{del}(5 q) \mathrm{MDS}$, while only $31 \%$ of 470 patients who had a code for $\operatorname{del}(5 q)$ MDS received the drug. Nonetheless, the percentage of patients with $\operatorname{del}(5 q)$ MDS who were prescribed lenalidomide increased over time, probably indicating increasing familiarity and experience of physicians with the drug. The authors observed that, in contrast with the drug approval label, only $33 \%$ of patients were RBC transfusion-dependent at the time of initiation of therapy. Physicians initiated lenalidomide therapy more rapidly for patients with $\operatorname{del}(5 q) \mathrm{MDS}$ than for other lower-risk MDS patients (median time to initiation from diagnosis 8 weeks versus 20 weeks; $P<0.01$, respectively). The use of lenalidomide was negatively associated with increasing age and baseline comorbidities. The authors noted that overall, the reduction in transfusion rates were consistent with clinical trials data, ie, $44 \%$ of transfusion-using/transfusion-dependent patients achieved reductions in transfusion use. Responses were more frequent among transfusion-dependent patients who received three or more cycles of therapy $(77 \%$ reduced their transfusion use and 40\% became transfusion-independent). Response rates were higher when three or more lenalidomide cycles were received. Among patients with transfusion using/ transfusion-dependent del(5q) MDS, 53\% achieved reductions in their need for transfusion. ${ }^{88}$

As previously mentioned, the data from MDS-004 suggest that lenalidomide is associated with improvement in quality of life among responders. However, data regarding cost-effectiveness from this trial are not available. Early data suggest that oral lenalidomide is cost-effective in the USA in the treatment of transfusion-dependent, low-risk, or intermediate-risk del(5q) MDS. Goss et al demonstrated that the cost of lenalidomide treatment was offset by reduced blood transfusion and erythropoietin costs. ${ }^{89}$

\section{Our approach and conclusion}

Currently, the approved indication of lenalidomide in MDS is restricted to IPSS lower-risk MDS patients with $\operatorname{del}(5 q)$ and symptomatic transfusion-dependent anemia. Although the dose of lenalidomide approved by the US Food and Drug Administration for $\operatorname{del}(5 \mathrm{q}) \mathrm{MDS}$ is $10 \mathrm{mg}$ daily, in clinical practice doses of 5-10 mg for 21-28 days of 28 days are usually used. If well tolerated, responders should continue treatment indefinitely. ${ }^{1}$ Lower doses and/ or an intermittent schedule might be used if toxicity occurs. Myelosuppression is the most common side effect of lenalidomide. Blood counts should be checked weekly for the first 8 weeks and then monthly thereafter. Adding granulocyte colony-stimulating factors can be considered once the neutrophil count is less than $1,000 \times 10^{6}$ cells $/ \mathrm{L} .{ }^{90}$ We usually hold treatment until the neutrophil count is $>500 \times 10^{6}$ cells $/ \mathrm{L}$. We also hold treatment if the platelet count is less than $50 \times 10^{9}$ cells/ $\mathrm{L}$ and resume it once counts are above $50 \times 10^{9} / \mathrm{L} .{ }^{90}$ The reported incidence of VTE in lenalidomide-treated patients in the Groupe Francophone des Myélodysplasies, MDS-001, MDS-003, and MDS-004 studies is relatively low (3.4\%). ${ }^{45,57,58,91}$ Prophylaxis for deep vein thrombosis is generally not recommended. However, VTE prophylaxis with low molecular weight heparin may be considered in patients with a prior VTE history. ${ }^{1,90}$ Evolving information suggests that testing for TP53 mutations should be incorporated into the prognostic score because of its potential impact on treatment choice in patients with del $(5 q)$ who are classified as low-risk to intermediate-risk based on current IPSS. Lenalidomide in non-del $(5 q)$ should be used for patients who are purely anemic; the National Comprehensive Cancer Network guidelines list lenalidomide as an option for treatment. The sequence of utilizing lenalidomide in lower risk non-del(5q) MDS may be of importance. For high-risk patients with $\operatorname{del}(5 q)$, lenalidomide is not recommended outside the context of a clinical trial at this time. Potential use of lenalidomide in these patient populations includes using higher doses of the drug as well as combining lenalidomide with other medications, such as hypomethylating agents. ${ }^{92}$ Future directions include finding biological markers to help in predicting responders in this population.

\section{Acknowledgment}

AMZ is supported by a Young Investigator Award from the American Society of Clinical Oncology (ASCO YIA) and 
by an Evans Fellow award from the MDS Clinical Research Consortium of the Aplastic Anemia and Myelodysplastic Syndromes International Foundation (AAMDSIF) and the Ed Evans Foundation.

\section{Disclosure}

The authors report no conflicts of interest in this work.

\section{References}

1. Leitch HA, Buckstein B, Shamy A, Storring JM. The immunomodulatory agents lenalidomide and thalidomide for treatment of the myelodysplastic syndromes: a clinical practice guideline. Crit Rev Oncol Hematol. 2013;85(2):162-192.

2. Mitchell M, Gore SD, Zeidan AM. Iron chelation therapy in myelodysplastic syndromes: where do we stand? Expert Rev Hematol. 2013;6(4): 397-410.

3. Huang TC, Ko BS, Tang JL, et al. Comparison of hypoplastic myelodysplastic syndrome (MDS) with normo-/hypercellular MDS by International Prognostic Scoring System, cytogenetic and genetic studies. Leukemia. 2008;22(3):544-550.

4. Malcovati L, Hellström-Lindberg E, Bowen D, et al. Diagnosis and treatment of primary myelodysplastic syndromes in adults: recommendations from the European LeukemiaNet. Blood. 2013;122(17):2943-2964.

5. Rådlund A, Thiede T, Hansen S, Carlsson M, Engquist L. Incidence of myelodysplastic syndromes in a Swedish population. Eur J Haematol. 1995;54(3):153-156.

6. Aul C, Giagounidis A, Germing U. Epidemiological features of myelodysplastic syndromes: results from regional cancer surveys and hospital-based statistics. Int J Hematol. 2001;73(4):405-410.

7. Germing U, Strupp C, Kündgen A, et al. No increase in age-specific incidence of myelodysplastic syndromes. Haematologica. 2004;89(8): 905-910.

8. Rollison DE, Howlader N, Smith MT, et al. Epidemiology of myelodysplastic syndromes and chronic myeloproliferative disorders in the United States, 2001-2004, using datat from the NAACCR and SEER programs. Blood. 2008;112(1):45-52.

9. Neukirchen J, Schoonen WM, Strupp C, et al. Incidence and prevalence of myelodysplastic syndromes: data from the Düsseldorf MDS-registry. Leuk Res. 2011;35(12):1591-1596.

10. Zeidan AM, Faltas B, Douglas Smith B, Gore S. Myelodysplastic syndromes: what do hospitalists need to know? J Hosp Med. 2013;8(6): 351-357.

11. Zeidan AM, Smith BD, Komrokji RS, Gore SD. Prognostication in myelodysplastic syndromes: beyond the International Prognostic Scoring System (IPSS). Am J Med. 2013;126(4):e25.

12. Faltas B, Zeidan AM, Gergis U. Myelodysplastic syndromes: toward a risk-adapted treatment approach. Expert Rev Hematol. 2013;6(5):611-624.

13. Zeidan AM, Komrokji RS. There's risk, and then there's RISK: The latest clinical prognostic risk stratification models in myelodysplastic syndromes. Curr Hematol Malig Rep. 2013;8(4):351-360.

14. Bennett JM, Catovsky D, Daniel MT, et al. Proposals for the classification of the myelodysplastic syndromes. Br J Haematol. 1982;51(2): 189-199.

15. Vardiman JW, Thiele J, Arber DA, et al. The 2008 revision of the World Health Organization (WHO) classification of myeloid neoplasms and acute leukemia: rationale and important changes. Blood. 2009;114(5): 937-951.

16. Greenberg P, Cox C, LeBeau MM, et al. International scoring system for evaluating prognosis in myelodysplastic syndromes. Blood. 1997;89(6): 2079-2088.

17. Malcovati L, Germing U, Kuendgen A, et al. Time-dependent prognostic scoring system for predicting survival and leukemic evolution in myelodysplastic syndromes. J Clin Oncol. 2007;25(23):3503-3510.
18. Greenberg PL, Tuechler H, Schanz J, et al. Revised international prognostic scoring system for myelodysplastic syndromes. Blood. 2012;120(12):2454-2465.

19. Bennett JM, Catovsky D, Daniel MT, et al. Proposals for the classification of the acute leukaemias. French-American-British (FAB) co-operative group. Br J Haematol. 1976;33(4):451-458.

20. Kantarjian H, O'Brien S, Ravandi F, et al. Proposal for a new risk model in myelodysplastic syndrome that accounts for events not considered in the original International Prognostic Scoring System. Cancer. 2008;113(6):1351-1361.

21. Eisenmann KM, Dykema KJ, Matheson SF, et al. 5q-myelodysplastic syndromes: chromosome $5 \mathrm{q}$ genes direct a tumor-suppression network sensing actin dynamics. Oncogene. 2009;28(39):3429-3441.

22. Voutsadakis IA, Cairoli A. A crtitical review of the molecular pathophysiology of lenalidomide sensitivity in 5q-myelodysplastic syndromes. Leuk Lymphoma. 2012;53(5):779-788.

23. Zeidan AM, Gore SD, Komrokji RS. Higher-risk myelodysplastic syndromes with del $(5 \mathrm{q})$ : is sequential azacitidine-lenalidomide combination the way to go? Expert Rev Hematol. 2013;6(3):251-254.

24. Faltas B, Zeidan A, Gergis U. Myelodysplastic syndromes: toward a risk-adapted treatment approach. Expert Rev Hematol. 2013;6(5): 611-624.

25. Boultwood J, Lewis S, Wainscoat JS. The 5q-syndrome. Blood. 1994;84(10):3253-3260.

26. Boultwood J, Pellagatti A, McKenzie ANJ, Wainscoat JS. Advances in the 5q-syndrome. Blood. 2010;116(26):5803-5811.

27. van Leeuwen BH, Martinson ME, Webb GC, Young IG. Molecular organization of the cytokine gene cluster, involving the human IL-3, IL-4, IL-5, and GM-CSF genes, on human chromosome 5. Blood. 1989;73(5):1142-1148.

28. Roberts WM, Look AT, Roussel MF, Sherr CJ. Tandem linkage of human CSF-1 receptor (c-fms) and PDGF receptor genes. Cell. 1988;55(4):655-661.

29. Van den Berghe H, Cassiman JJ, David G, Fryns JP, Michaux JL, Sokal G. Distinct haematological disorder with deletion of long arm of no 5 chromosome. Nature. 1974;251(5474):437-438.

30. Ebert BL. Deletion $5 \mathrm{q}$ in myelodysplastic syndrome: a paradigm for the study of hemizygous deletions in cancer. Leukemia. 2009;23(7): $1252-1256$.

31. Komrokji RS, Padron E, Ebert BL, List AF. Deletion 5q MDS: molecular and therapeutic implications. Best Pract Res Clin Haematol. 2013;26(4):365-375.

32. Giagounidis A, Mufti GJ, Fenaux P, Germing U, List A, MacBeth KJ. Lenalidomide as a disease-modifying agent in patients with $\operatorname{del}(5 \mathrm{q})$ myelodysplastic syndromes: linking mechanism of action to clinical outcomes. Ann Hematol. 2014;93(1):1-11.

33. Ebert BL, Pretz J, Bosco J, et al. Identification of RPS14 as a 5q-syndrome gene by RNA interference screen. Nature. 2008;451(7176): 335-339.

34. Narla A, Hurst SN, Ebert BL. Ribosome defects in disorders of erythropoiesis. Int J Hematol. 2011;93(2):144-149.

35. Shi D, Gu W. Dual roles of MDM2 in the regulation of p53: ubiquitination dependent and ubiquitination independent mechanisms of MDM2 repression of p53 activity. Genes Cancer. 2012;3(3-4):240-248.

36. Starczynowski DT, Kuchenbauer F, Argiropoulos B, et al. Identification of miR-145 and miR-146a as mediators of the 5q-syndrome phenotype. Nat Med. 2010;16(1):49-58.

37. Starczynowski DT, Karsan A. Deregulation of innate immune signaling in myelodysplastic syndromes is associated with deletion of chromosome arm 5q. Cell Cycle. 2010;9(5):855-856.

38. Lehmann S, O’Kelly J, Raynaud S, Funk SE, Sage EH, Koeffler HP. Common deleted genes in the 5q-syndrome: thrombocytopenia and reduced erythroid colony formation in SPARC null mice. Leukemia. 2007;21(9):1931-1936.

39. Adès L, Fenaux P. Immunomodulating drugs in myelodysplastic syndromes. Hematology Am Soc Hematol Educ Program. 2011;2011: 556-560. 
40. Kelaidi C, Park S, Brechignac S, et al. Treatment of myelodysplastic syndromes with $5 \mathrm{q}$ deletion before the lenalidomide era; the GFM experience with EPO and thalidomide. Leuk Res. 2008;32(7):1049-1053.

41. Raza A, Meyer P, Dutt D, et al. Thalidomide produces transfusion independence in long-standing refractory anemias of patients with myelodysplastic syndromes. Blood. 2001;98(4):958-965.

42. Moreno-Aspitia A, Colon-Otero G, Hoering A, et al. Thalidomide therapy in adult patients with myelodysplastic syndrome. A North Central Cancer Treatment Group Phase II trial. Cancer. 2006; 107(4):767-772.

43. Strupp C, Hildebrandt B, Germing U, Haas R, Gattermann N. Cytogenetic response to thalidomide treatment in three patients with myelodysplastic syndrome. Leukemia. 2003;17(6):1200-1202.

44. Wei S, Chen X, McGraw K, et al. Lenalidomide promotes p53 degradation by inhibiting MDM2 auto-ubiquitination in myelodysplastic syndrome with chromosome 5q deletion. Oncogene. 2013;32(9):1110-1120.

45. List A, Dewald G, Bennett J, et al. Lenalidomide in the myelodysplastic syndrome with chromosome 5q deletion. N Engl J Med. 2006;355(14): 1456-1465.

46. Narla A, Dutt S, McAuley JR, et al. Dexamethasone and lenalidomide have distinct functional effects on erythropoiesis. Blood. 2011;118(8): 2296-2304.

47. List AF, Estes M, Williams A, et al. Lenalidomide (CC-5013; Revlimid) promotes erythropoiesis in myelodysplastic syndromes (MDS) by CD45 protein tyrosine phosphatase (PTP) inhibition. ASH Annual Meeting Abstracts. 2006;108:1360.

48. Komrokji RS, List AF. Role of lenalidomide in the treatment of myelodysplastic syndromes. Semin Oncol. 2011;38(5):648-657.

49. Corral LG, Haslett PA, Muller GW, et al. Differential cytokine modulation and $\mathrm{T}$ cell activation by two distinct classes of thalidomide analogues that are potent inhibitors of TNT-alpha. J Immunol. 1999;163(1): 380-386.

50. Symeonidis A, Kourakli A, Katevas P, et al. Immune function parameters at diagnosis in patients with myelodysplastic syndromes: correlation with the FAB classification and prognosis. Eur J Haematol. 1991;47(4):277-281.

51. Kotla V, Goel S, Nischal S, et al. Mechanism of action of lenalidomide in hematological malignancies. J Hematol Oncol. 2009;2:36.

52. Epling-Burnette PK, Han Y, Mailloux AW, et al. Novel predictor of lenalidomide response in non-del5q MDS reveals linkage to molecular mechanism: first characterization of T-cell function in cereblon homozygous deficient mice. 55th ASH Annual Meeting and Exposition. 2013. Available from: https://ash.confex.com/ash/2013/webprogram/ Paper65378.html. Accessed August 28, 2014.

53. Gupta D, Treon SP, Shima Y, et al. Adherence of multiple myeloma cells to bone marrow stromal cells upregulates vascular endothelial growth factor secretion: therapeutic applications. Leukemia. 2001;15(12): 1950-1961.

54. Teo SK. Properties of thalidomide and its analogues: implications for anticancer therapy. AAPS J. 2005;7(1):E14-E19.

55. Giagounidis AA, Germing U, Haase S, et al. Clinical, morphological, cytogenetic, and prognostic features of patients with myelodysplastic syndromes and del(5q) including band q31. Leukemia. 2004;18(1): 113-119.

56. Scherman E, Malak S, Perot C, Gorin NC, Rubio MT, Isnard F. Interest of the association azacitidine-lenalidomide as frontline therapy in highrisk myelodysplasia or acute myeloid leukemia with complex karyotype. Leukemia. 2012;26(4):822-824.

57. List A, Kurtin S, Roe DJ, et al. Efficacy of lenalidomide in myelodysplastic syndromes. N Engl J Med. 2005;352(6):549-557.

58. Fenaux P, Giagounidis A, Selleslag D, et al. A randomized phase 3 study of lenalidomide versus placebo in RBC transfusion-dependent patients with low-/intermediate-1-risk myelodysplastic syndromes with del5q. Blood. 2011;118(14):3765-3776.

59. List AF, Bennett JM, Sekeres MA, et al. Extended survival and reduced risk of AML progression in erythroid-responsive lenalidomide-treated patients with lower-risk del(5q) MDS. Leukemia. 2014;28(5): 1033-1040.
60. Oliva EN, Latagliata R, Morabito F, et al. Lenalidomide for the treatment of low- and int-1-risk MDS with del(5q): efficacy and quality of life study. Blood. 2009;114(2):1080.

61. Göhring G, Giagounidis A, Büsche G, et al. Patients with del(5q) MDS who fail to achieve sustained erythroid or cytogenetic remission after treatment with lenalidomide have an increased risk for clonal evolution and AML progression. Ann Hematol. 2010;89(4): 365-374.

62. Adès L, Le Bras F, Sebert M, et al. Treatment with lenalidomide does not appear to increase the risk of progression in lower risk myelodysplastic syndromes with $5 \mathrm{q}$ deletion. A comparative analysis by the Groupe Francophone des Myelodysplasies. Haematologica. 2012;97(2): 213-218.

63. Kuendgen A, Lauseker M, List AF, et al. Lenalidomide does not increase AML progression risk in $\mathrm{RBC}$ transfusion-dependent patients with low- or intermediate-1-risk MDS with del $(5 q)$ : a comparative analysis Leukemia. 2013;27(5):1072-1079.

64. Adès L, Boehrer S, Prebet T, et al. Efficacy and safety of lenalidomide in intermediate-2 or high-risk myelodysplastic syndromes with 5 q deletion: results of a phase 2 study. Blood. 2009;113(17): 3947-3952.

65. Möllgård L, Saft L, Treppendahl MB, et al. Clinical effect of increasing doses of lenalidomide in high-risk myelodysplastic syndrome and acute myeloid leukemia with chromosome 5 abnormalities. Haematologica. 2011;96(7):963-971.

66. Raza A, Reeves JA, Feldman EJ, et al. Phase 2 study of lenalidomide in transfusion-dependent, low-risk, and intermediate-1 risk myelodysplastic syndromes with karyotypes other than deletion $5 \mathrm{q}$ Blood. 2008;111(1):86-93.

67. Ebert BL, Galili N, Tamayo P, et al. An erythroid differentiation signature predicts response to lenalidomide in myelodysplastic syndrome. PLoS One. 2008;5(2):e35.

68. Toma A. A randomized study of lenalidomide (LEN) with or without EPO in RBC transfusion dependent (TD) IPSS low and int-1 (lower risk) myelodysplastic syndromes (MDS) without del $5 \mathrm{q}$ resistant to EPO. J Clin Oncol. 2013;31(Suppl 15):Abstr 7002.

69. Jädersten M, Saft L, Smith A, et al. TP53 mutations in low-risk myelodysplastic syndromes with $\operatorname{del}(5 \mathrm{q})$ predict disease progression J Clin Oncol. 2011;29(15):1971-1979.

70. Giagounidis AA. Lenalidomide for $\operatorname{del}(5 q)$ and non-del $(5 q)$ myelodysplastic syndromes. Semin Hematol. 2012;49(4):312-322.

71. Mallo M, Del Rey M, Ibáñez M, et al. Response to lenalidomide in myelodysplastic syndromes with $\operatorname{del}(5 \mathrm{q})$ : influence of cytogenetics and mutations. Br J Haematol. 2013;162(1):74-86.

72. Fernandez-Mercado M, Burns A, Pellagatti A, et al. Targeted resequencing analysis of 25 genes commonly mutated in myeloid disorders in del(5q) myelodysplastic syndromes. Haematologica. 2013;98(12):1856-1864.

73. Sugimoto Y, Sekeres MA, Makishima H, et al. Cytogenetic and molecular predictors of response in patients with myeloid malignancies without $\operatorname{del}[5 \mathrm{q}]$ treated with lenalidomide. J Hematol Oncol. 2012;5:4.

74. Wu L, Li X, Xu F, Zhang Z, Chang C, He Q. Low RPS14 expression in MDS without $5 q-$ aberration confers higher apoptosis rate of nucleated erythrocytes and predicts prolonged survival and possible response to lenalidomide in lower risk non-5q-patients. Eur J Haematol. 2013;90(6):486-493.

75. Sardnal V, Rouquette A, Kaltenbach S, et al. A G polymorphism in the $\mathrm{CRBN}$ gene acts as a biomarker of response to treatment with lenalidomide in low/int-1 risk MDS without $\operatorname{del}(5 q)$. Leukemia. 2013;27(7): 1610-1613.

76. Caceres G, McGraw K, Yip BH, et al. TP53 suppression promotes erythropoiesis in $\operatorname{del}(5 \mathrm{q}) \mathrm{MDS}$, suggesting a targeted therapeutic strategy in lenalidomide-resistant patients. Proc Natl Acad Sci US A. 2013;110(40):16127-16132.

77. Tehranchi R, Woll PS, Anderson K, et al. Persistent malignant stem cells in del(5q) myelodysplasia in remission. $N$ Engl J Med. 2010;363(11): 1025-1037. 
78. Komrokji RS, Lancet JE, Swern AS, et al. Combined treatment with lenalidomide and epoetin alfa in lower-risk patients with myelodysplastic syndrome. Blood. 2012;120(17):3419-3424.

79. Wang ES, Lyons RM, Larson RA, et al. A randomized, double-blind, placebo-controlled phase 2 study evaluating the efficacy and safety of romiplostim treatment of patients with low or intermediate-1 risk myelodysplastic syndrome receiving lenalidomide. J Hematol Oncol. 2012;5:71.

80. Wörmann B. Clinical indications for thrombopoietin and thrombopoietinreceptor agonists. Transfus Med Hemother. 2013;40(5):319-325.

81. Sekeres MA, Tiu RV, Komrokji R, et al. Phase 2 study of the lenalidomide and azacitidine combination in patients with higher-risk myelodysplastic syndromes. Blood. 2012;120(25):4945-4951.

82. Platzbecker U, Braulke F, Kündgen A, et al. Sequential combination of azacitidine and lenalidomide in $\operatorname{del}(5 q)$ higher-risk myelodysplastic syndromes or acute myeloid leukemia: a phase I study. Leukemia. 2013;27(6):1403-1407.

83. Garcia-Manero G, Daver NG, Borthakur G, et al. Phase I study of the combination of 5-azacitidine sequentially with high-dose lenalidomide in higher-risk myelodysplastic syndrome (MDS) and acute myelogenous leukemia (AML). Blood. 2011;118:1122.

84. Platzbecker U, Germing U. Combination of azacitidine and lenalidomide in myelodysplastic syndromes or acute myeloid leukemia - a wise liaison? Leukemia. 2013;27(9):1813-1819.

85. Fenaux P, Mufti GJ, Hellstrom-Lindberg E, et al. Efficacy of azacitidine compared with that of conventional care regimens in the treatment of higher-risk myelodysplastic syndromes: a randomised, open-label, phase III study. Lancet Oncol. 2009;10(3): 223-232.

86. Zeidan AM, Linhares Y, Gore SD. Current therapy of myelodysplastic syndromes. Blood Rev. 2013;27(5):243-259.
87. Raza A, Galili N, Mulford D, et al. Phase 1 dose-ranging study of ezatiostat hydrochloride in combination with lenalidomide in patients with non-deletion (5q) low to intermediate-1 risk myelodysplastic syndrome (MDS). J Hematol Oncol. 2012;5:18.

88. Zeidan AM, Gore SD, McNally DL, et al. Lenalidomide performance in the real world: patterns of use and effectiveness in a Medicare population with myelodysplastic syndromes. Cancer. 2013;119(21): $3870-3878$

89. Goss TF, Szende A, Schaefer C, et al. Cost effectiveness of lenalidomide in the treatment of transfusion-dependent myelodysplastic syndromes in the United States. Cancer Control. 2006;13 Suppl:17-25.

90. Duong VH, Komrokji RS, List AF. Efficacy and safety of lenalidomide in patients with myelodysplastic syndrome with chromosome $5 \mathrm{q}$ deletion. Ther Adv Hematol. 2012;3(2):105-116.

91. Le Bras F, Sebert M, Kelaidi C, et al. Treatment by Lenalidomide in lower risk myelodysplastic syndrome with $5 \mathrm{q}$ deletion - the GFM experience. Leuk Res. 2011;35(11):1444-1448.

92. Zeidan AM, Kharfan-Dabaja MA, Komrokji RS. Beyond hypomethylating agents failure in patients with myelodysplastic syndromes. Curr Opin Hematol. 2014;21(2):123-130.

93. Barlow JL, Drynan LF, Hewett DR, et al. A p53-dependent mechanism underlies macrocytic anemia in a mouse model of human $5 \mathrm{q}$-syndrome. Nat Med. 2010;16(1):59-66.

94. Wei S, Chen X, Rocha K, et al. A critical role for phosphatase haplodeficiency in the selective suppression of deletion 5q MDS by lenalidomide. Proc Natl Acad Sci U S A. 2009;106(31):12974-12979.

95. DeWard AD, Leali K, West RA, Prendergast GC, Alberts AS. Loss of RhoB expression enhances the myelodysplastic phenotype of mammalian diaphanous-related Formin mDia1 knockout mice. PLoS One. 2009;4(9):e7102.
Journal of Blood Medicine

\section{Publish your work in this journal}

The Journal of Blood Medicine is an international, peer-reviewed, open access, online journal publishing laboratory, experimental and clinical aspects of all topics pertaining to blood based medicine including but not limited to: Transfusion Medicine; Blood collection, Donor issues, Transmittable diseases, and Blood banking logistics; Immunohematology; Artificial and alternative

\section{Dovepress}

blood based therapeutics; Hematology; Biotechnology/nanotechnology of blood related medicine; Legal aspects of blood medicine; Historical perspectives. The manuscript management system is completely online and includes a very quick and fair peer-review system. Visit http://www.dovepress.com/ testimonials.php to read real quotes from published authors. 